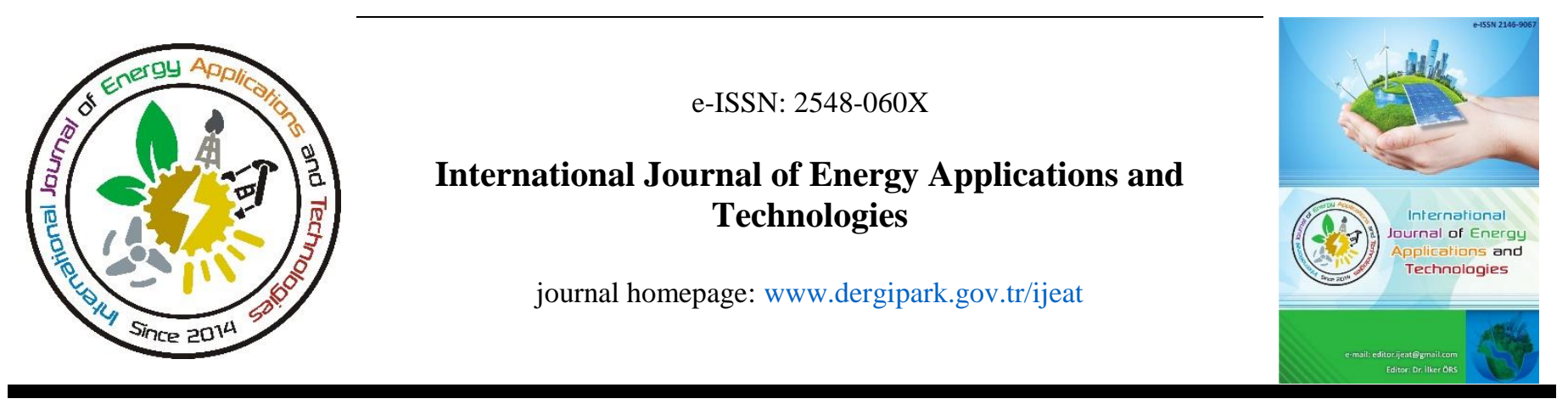

Original Research Article

\title{
Experimental investigation of heat transfer in aluminum wings with NACA 4040 profile
}

\author{
Adnan Berber ${ }^{*}$, Muhammed Yetimoğlu² \\ ${ }^{I}$ Department of Mechanical Engineering, Faculty of Technology, Selcuk University, Konya, Türkiye \\ ${ }^{2}$ Department of Mechanical Engineering, Seydișehir Ahmet Cengiz Faculty of Engineering, Necmettin Erbakan University, Konya, Türkiye
}

\author{
ARTICLE INFO \\ * Corresponding author \\ aberber@selcuk.edu.tr \\ Received June 5, 2020 \\ Accepted December 22, 2021 \\ Published by Editorial Board \\ Members of IJEAT \\ (C) This article is distributed by \\ Turk Journal Park System under \\ the CC 4.0 terms and conditions. \\ doi: $10.31593 /$ ijeat. 748491
}

\begin{abstract}
Heat transfer is a working area where different numerical results are obtained from different materials, different environments, independent observations are made, data can be collected at different bases based on the abundance of data input. effects on heat transfer. The effects of air flow, air temperature and air pressure on heat transfer were discussed. Unlike the previous studies, the construction of the fin is made of aluminum and the choice of the NACA 4040 wing profile as the shape of the fin was one of the major factors in the differences in the test output. Since the results obtained from the experiments included many products or development factors in the application and production areas that are important, the fact that this study was carried out with aluminum material and the results of the experiments in this direction became a factor increasing the circulation in these processes. In our studies, one type of fin was used.
\end{abstract}

Keywords: Convection heat transfer, Heat exchanger, Winglet surfaces, NACA 4040 profile

\section{Introduction}

Heat transfer devices such as exchangers, boilers, condensers, radiators, heaters, stoves, coolers, and solar collectors are designed by making heat transfer analysis the priority. The heat transfer problems faced in practice can be divided into two categories. These are heat transfer speed calculation and dimensioning problems. Heat transfer speed calculation problems focus on determining the heat transfer speed in an existing system for a certain temperature difference. Dimensioning problems on the other hand focus on determining the dimensions of a system to transfer heat at a determined speed in the case of a defined temperature difference. An engineering mechanism or process can be analyzed both experimentally and analytically. While the experimental approach has the advantage of allowing the examination of the real physical system, the desired quantity is determined via measurements within the limits of experimental mistakes. Yet this approach is rather expensive, time-consuming, and mostly not practical. For instance, the whole heating system of a building is generally dimensioned before the building is constructed based on the features provided for that building. Therefore, the analytical approach is favored as it is both fast and cheap. However, the achieved results depend on the precision of the admissions, approaches, and idealization. In heat transfer works, adaptation is achieved most of the time by analyzing various options and reducing them to a few, and then experimentally verifying the findings [1].

One of the most important areas of use for heat transfer is forced convection in in-pipe flows. Studies have been conducted in this area to improve the heat transfer. Besides, the amount of friction factor and pumping power are included in the research of many studies. Method of placing materials in the pipe to expand the surface area to enhance the heat transfer used while conducting these experimental studies has been used for a very long time and there are still studies going on in our current day. In our study, we are trying to do something that has never been done before by sticking pins 
in the pipe. In order to make sure that our study is authentic, we have conducted a literature research of a great scale. In one of these, Daric1 has experimentally analyzed the impact of an orifice-shaped plugging element placed at the entry in a pipe heated using the walls as resistance where the constant surface heat flux is at boundary condition and in turbulent airflow on the heat transfer [2].

Sara et al. have placed rectangular perforated pipe sections in a rectangular pipe and observed the heat transfer and the difference in pressures. While conducting this study, they have examined various hole diameters and plate numbers [3]. In mechanical engineering, it is important to determine the heat transfer of fluid flow in various geometries. Such calculations are used directly in a wide range of industrial purposes such as synthesizing, designing, and optimizing the performance of various processes and systems. For example, evaluating forced convective heat transfer in closed channels is important when designing systems such as, heat exchangers.

In Many studies have employed analytical, numerical, and experimental approaches to evaluate the effect of different cross-sectional shapes, Previous studies of heat transfer in non-circular ducts have been mostly limited to numerical and experimental analysis. Many numerical studies have investigated rectilinear convective heat transfer in closed channels.

Berber et al. Firstly, laminar and forced convective heat transfer was studied in Circular Channels [4]. They used the Using Artificial Neural Network to obtain numerical solutions for fully developed conditions [5].

They also developed formulations for the concept of thermally fully developed conditions for both constant heat flux and wall.

In contrast to Berber et al., who used pins attached to the surface for heat transfer in circular pipes, Altun et al. used inpipe elements in their work [6,7]. Improvement of heat transfer by using curved fins as a turbulator in rectangular ducts has also been done [8].

Wang and Chen have conducted measurements by making changes in the duct surface geometry. By conducting measurements at different Reynolds values, they have observed the values of Prandtl, Nusselt, and pressure differences [9].

Akyol and Bilen (2006) have placed rectangular wings in a duct and conducted their study this way. In that study, they have examined the heat transfer and friction values experimentally. They have conducted measurements at different Reynolds values in this study. While conducting the study, they have changed the placement layout and distances $[10,11]$.

Sewall et al. have observed the flow properties and their impact on the heat transfer by placing materials inside the pipe. As in other studies, materials placed to create a turbulent effect were successful as well and they created an improved heat transfer [12].

Tijing et al. have observed the impact of a star-shaped aluminum piece placed on a counter-current flow heat exchanger. In this study, they examined the heat transfer and pressure drop differences. They have conducted their study on straight and wound aluminum and compared the results. They have reached the conclusion that straight aluminum allows a better heat transfer [13].

Yakut et al. have conducted their study using wings they placed in a heat exchanger. In this study, they have made measurements according to the arrangement shape of the wings and the distance between them. They have observed heat transfer and pressure differences in the measurements conducted [14].

Didarul et al. have placed rectangular wings in a rectangular pipe. In this study, they have determined the changes in the heat transfer and flow properties. They have conducted measurements by changing the wing arrangement shape and wing placement layout. In this study, as in others, they have achieved better results compared to pipes without pins [15]. Hiravennavar et al. have conducted measurements by placing wings of various geometry inside the duct. While conducting this study, they have carried out measurements by changing the thickness of the wings. They have observed an improvement in the heat transfer in this study [16].

Khaled have conducted their study using rectangular wings. In this study, it has been observed that heat transfer was better in a duct with wings compared to an empty duct. Again, in this study, thermal conductivity and heat convection have been examined [17]. Aharwal et al. have placed rectangular pieces in a rectangular pipe and observed their impact on heat transfer and pressure differences. While placing the rectangular pieces, they have considered the number and inclination of the wings. Therefore, they have examined the turbulator effect [18].

Şahin and Demir have studied the heat transfer and pressure difference of square wings placed in a rectangular duct. In this study, they have conducted measurements at different Reynolds values. Also, they have conducted their measurements by changing the length and placement distances of the wings in this study [19].

Luviano et al. have observed the heat transfer by placing heated plates in horizontal ducts consisting of parallel plates. In this study, they have observed an increase in the heat transfer.

Bilen et al. have conducted measurements by making changes in the inner surface geometry of the pipes. They have conducted these measurements at various Reynolds values. In this study, the heat transfer and friction variations have been observed. As in other studies, they have determined in 
this study as well that the heat transfer in the pipe with changed inner surface geometry is better compared to the pipe without pins.

Shaeri and Yaghoubi have mounted a wing on a plate and have done their measurements in this fashion. In this study, they have examined the impact of wings on the heat transfer. Again, in this study, they have conducted measurements at various Reynolds values [20].

Güneş S. has studied the impact of helically wound wires placed in a pipe on the heat transfer and flow properties at the 3514-27188 interval of Reynolds number. It has been observed that the results achieved via these studies with a pipe without pins are consistent with the results in the literature. They have conducted their study by placing a helically wound wire in a pipe [21].

Zhang et al. have aimed to study the heat transfer and flow properties experimentally. In their experiments, they have used type 14 micro wing structure. Considering height, width, distance between two wings, and the number of wings, they have calculated Nusselt number and the friction factor. They have conducted their measurements at the 128-5645 interval of Nusselt number [22].

Ziyan et al. have examined a concentric ring-shaped piece's impact on heat conductivity and pressure drop. They have conducted experiments for a three-winged pipe with spiral intervals and an empty pipe. They have worked between Reynolds 1428-3008 values.

Eren and Çalışkan have researched Nusselt number and the friction values experimentally by using cylindrical pins and triangle pins in a pipe with rectangular ducts. Air has been used as fluid. They have placed pins in the ducts vertically. They have used an infrared thermal camera in determining the temperature [23].

Yang et al. have studied the total heat absorber volume, pin material volume, and pressure drop. They have tried to determine the ideal number of pins to use in the study [24].

Badescu has aimed in the study at minimizing the pin volume for the given value of transferred heat flow. They have sued circular pins in the study. They have conducted studies with subdued convection and free thermal convection [25].

\section{General}

The schematic picture of the experiment system with a rectangular perpendicular duct is shown in Figure 1. There are prop holes on this perpendicular duct to allow the measurement of the speed and temperature of the liquid flowing inside the duct. Via these holes, the speed of the fluid in the duct, wing surface temperature from three different spots, and the body temperature along with system entry and output temperatures have been measured with the help of the mentioned speed and temperature props.
Moreover, the schematic picture of the experiment element placed inside the perpendicular duct in the system is shown in Figure 2 and the duct width, height, and the features of the wings are given respectively. The wings on the experiment element have been mounted to the body surface with the method of shrink fit by processing in a CNC milling machine. The experimental setup consists of three parts as entry, testing, and output parts. Using the motor and fan at the entry part, the air volume and speed are adjusted. The constant heat flux at the testing section has been achieved by using resistance. The pressure difference in the testing section has been measured by a differential pressure gauge with the help of tubes connected to the entry and output parts. Air speed is measured by an airspeed gauge device from the center of the pipe. The temperature changes on the pipe in the testing section is measured by a temperature collector device using thermocouples. In addition, the friction coefficient has been examined by observing the effect of inner elements placed inside the pipe on the pressure difference. While conducting this study, a constant heat flux has been achieved with the help of an extended surface resistance made of aluminum 6061. Thus, the speed values of the air have been determined in accordance with the Reynolds numbers, and measurements were conducted by each time creating different values at these speed values. In the experiment, the wing resistance method was used. Therefore, it was aimed to create an equal temperature distribution on the extended surface structure.

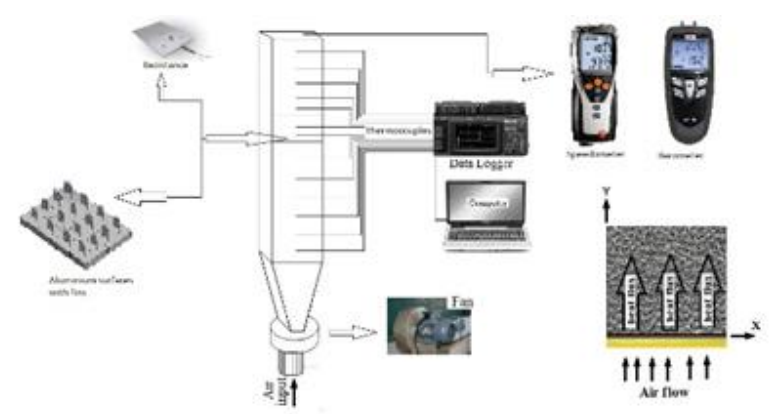

Fig. 1. General view of the experimental setup

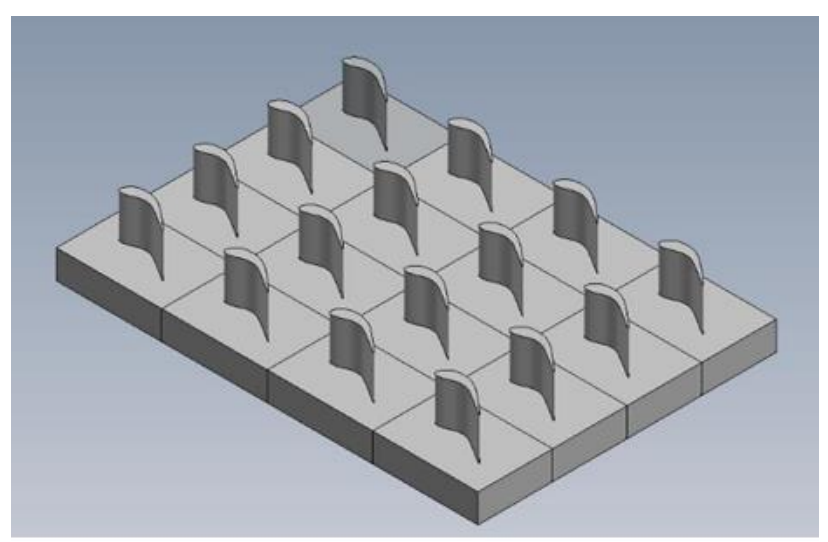

Fig. 2. Wing with $30^{\circ}$ angle 
As liquid, air was used while conducting this experiment. This air was then carried using a fan and circulated in the pipe constantly.

For the measurements, the airflow in the pipe was increased. System is not a closed one. The air was constantly flowing but at the end of the system, it was released into the atmosphere.

As a flow canal, a $4000 \mathrm{~mm}$ long, 200x50 mm rectangular duct was designed and produced with a galvanized sheet. A circular entry section of $20 \mathrm{~cm}$ diameter was added to the entry section of this duct. A 200x350 mm cap was opened $1600 \mathrm{~mm}$ away from the duct entry and the extended winglet surfaces designed were attached to this cap for testing. As an extended winglet surface, wing with $30^{\circ}$ Angle specially produced with a CNC using aluminum 6061 material was used in the experimental setup. Wings were in the form of NACA 4040 wing and they were designed with an inclination of 30 degrees to be able to test the differences in the flow in the duct aerodynamically. Parts were processed as a whole in the CNC by machining from an aluminum plate of $40 \mathrm{~mm}$ thickness. If the plate and wings had been separately processed and pieced together with solder, they would be rather inexpensive. However, because there would be a second material in the thermal conduction and there might be gaps left between, it actually would increase the losses in the process. Therefore, it was preferred to have the heat transfer block to be produced as a single piece.

\section{Experiment Results for Surface with $30^{\circ}$ Angle Wing}

In the study, the impact of a 30-degree angle wing on heat exchange and pressure drop was examined. Firstly, the impact of the 30-degree angle wing on heat exchange and flow properties were examined. Heat exchange for 30-degree angle aluminum wing through the duct according to this is shown in Figures 3 to 6 . The first deduction that can be made using the figures is that it decreases a bit due to the additional turbulence created but then it continues while increasing through the duct. Liquid temperature, as seen in the figures, has increased linearly from testing duct entrance to the wing, and during the contact with the wind, the temperature increase of the liquid has been achieved. The liquid temperature almost linearly increases up until the duct output section as well.

Through the pipe, change in the wing temperature values according to resistance temperatures at different Reynolds numbers are shown in Figures 3 to 6 . When we consider Figure 4.6, we see that the wing temperature generally varies for all Reynolds numbers. It is believed that this occurs because the air crashes the wings and forms a flow separation; therefore, creating additional turbulence, fluctuation, and swirls, and causing sudden increases in the convection coefficients.

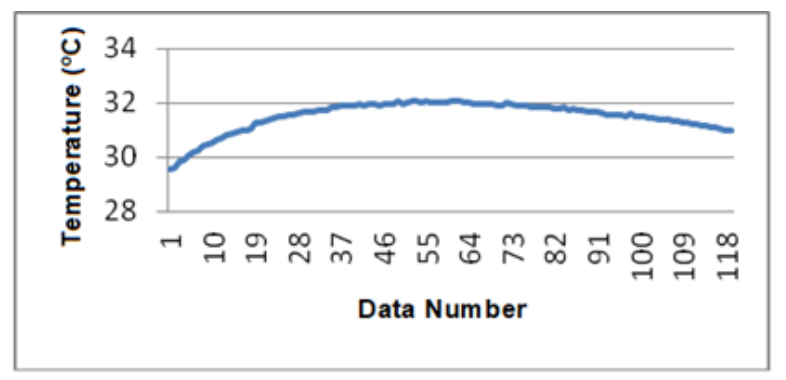

Fig. 3. Heat exchange of the wing at $30^{\circ}$ [Reynolds: 8588]

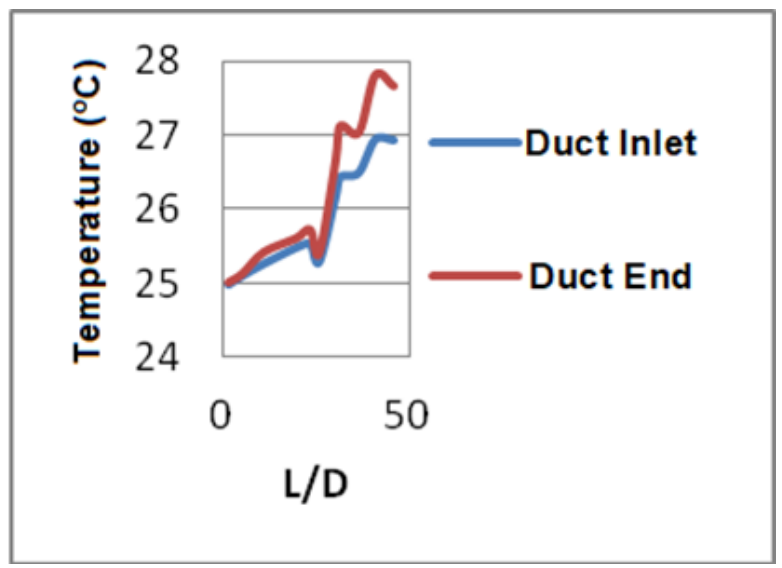

Fig. 4. Heat exchange of the liquid through the duct at $30^{\circ}$ wing [Reynolds: 8588]

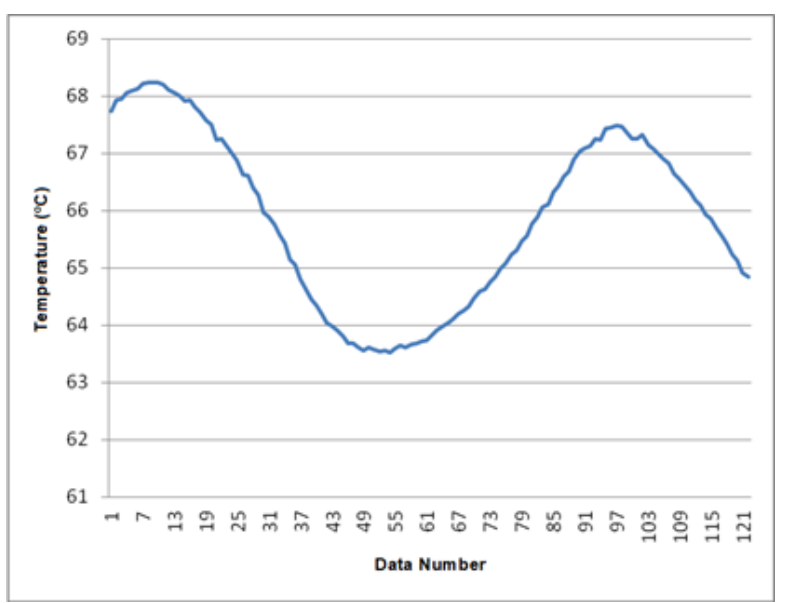

Fig. 5. Heat exchange of the wing at $70^{\circ}$ (Reynolds: 13378)

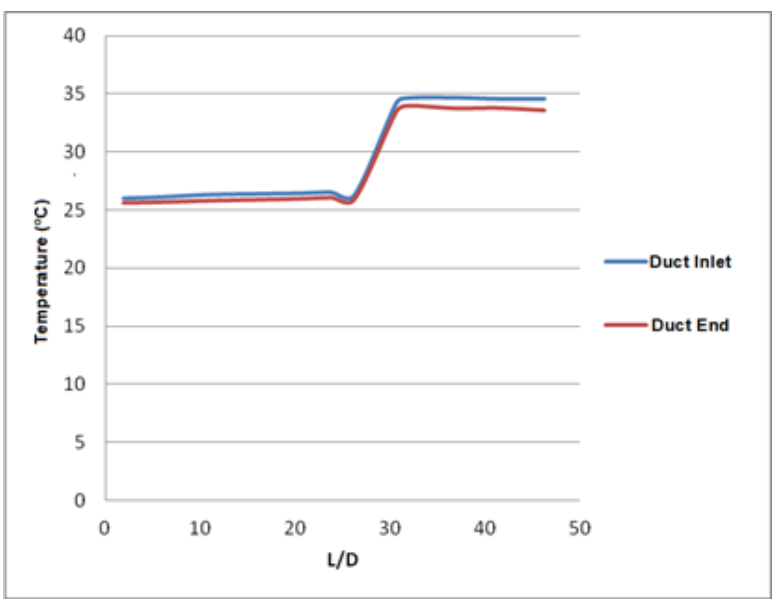

Fig. 6. Heat exchange of the liquid through the duct at $70^{\circ}$ wing [Reynolds: 13378] 


\section{Results}

In this study, the impact of the subdued flow and constant surface flow with the heated winged surface on heat transfer at the 10000 - 50000 interval of Reynolds number has experimentally analyzed. The results achieved from the experiments where an empty duck was used have been observed to be consistent with the literature. In the experiments, different from the winged plate used in literature, a surface with 2 different wings were used. 3 different measurements were made in total. For each measurement, temperatures were detected at 27 Reynolds [at 5000 - 20000 interval] numbers and the increase in the heat transfer and pressure drops were determined.

In the study, effort was made to keep the power of the tuned transformer constant and the variable parameter was reduced. The experiments were conducted in a closed environment.

The results achieved in this study are as follows;

Nusselt value acquired via measurements conducted with wings is observed to be higher than that of the empty duct. In the test conducted with wing, there are sudden increases in the Nusselt value at the entry section and then these sudden pikes decrease and continue at a constant value. The reason for this is that the turbulence was significantly high.

It has been observed that the net thermal improvement has almost the same values for winged surfaces. In winged surfaces' low Re numbers, net thermal improvement gets values close to one. It has been observed that the higher the Reynolds number gets in the winged surfaces, the lower the net thermal improvement gets.

\section{ORCID}

A. Berber

M. Yetimoğlu

$0000-0002-7797-7915$

0000-0002-2230-2603

\section{References}

[1] Çengel, Y. Isı ve Kütle Transferi. G. Kitabevi (Ed.). İzmir. 2014.

[2] Darıcı, S. 1998. Borularda Akış Tıkanmasının Türbülanslı Isı Transferine Etkileri. Içinde Selçuk Üniversitesi Makina Anabilim Dalı, Yüksek Lisans Tezi. Konya.

[3] Sara, O. N. 2001. Heat Transfer Enhancement in a Channel Flow with Perforated Rectangular Blocks. International Journal of Heat and Fuid Flow.

[4] Berber, A, Bağırsakçı, K, Gürdal, M. 2020. Investigation of Effects on Heat Transfer and Flow Characteristics of Cr-Ni Alloy and Aluminum Pins Placed in AISI 304 Tube, Thermal Science. 24(3), 1999-2011.
[5] Berber, A, Bağırsakçı, K, Gürdal, M. 2021. Prediction of Heat Transfer in a Circular Tube with Aluminium and Cr-Ni Alloy Pins Using Artificial Neural Network. Experimental Heat Transfer, 34(6), 547-563.

[6] Altun, A. H., Gurdal, M., Berber, A. 2019. The Effects of Sinusoidal Strip Element with Different Amplitudes on Heat Transfer and Flow Characteristics of Circular Channels. Heat Transfer Research, 50(6), 605-616.

[7] Altun, A. H., Gurdal, M., Berber, A. 2020. Effects of sinusoidal turbulator in cylindrical channel on heat transfer and flow characteristics. Maejo International Journal of Science and Technology Maejo Int. J. Sci. Technol., 14(01), 27-42.

[8] Berber, A, Gürdal, M., Yetimoğlu, M. 2021. Experimental Study on the Heat Transfer Enhancement in a Rectangular Channel with Curved Winglets. Experimental Heat Transfer, 1-21, in-press.

[9] Wang, C. et al. 2002. Forced Convection in a Wavy Wall Channel. International Journal of Heat and Mass Transfer. 45(12), 2587-2595.

[10] Akyol, U. et al.2006. Heat Transfer and Thermal Performance of a Surface with Hollow Rectangular Fins. Applied Thermal Engineer, 26(2), 209-216.

[11] Bilen, K. et al.2009. The Investigation of Grrove Geometry Effect on Heat Transfer for Internally Grooved Tubes. Applied Thermal Engineer, 29(4), 753761.

[12] Sewall, E. A. et al.2006. Experimental Validation of Large Eddy Simulations of Flow and Heat Transfer in a Stationary Ribbed Duet. International Journal of Heat and Fuid Flow, 27, 243-258.

[13] Tijing, L. et al.2006. A Study on Heat Transfer Enhancement Using Straigt and Twisted Internal Fin Insert. International Communications in Heat and Mass Transfer, 33, 719-726.

[14] Yakut, K. et al.2006. Optimum design Parameters of a Heat Exchanger Having Hexagonal Fins. Applied Energy, 83(2), 82-98.

[15] Didarul, M. et al.2007. Study on Heat Transfer and Fluid Flow Characteristics with Short Rectangular Plate Fin of Different Pattern. Experimental Thermal and Fluid Science, 31(4), 367-379.

[16] Hiravennar, S. et al.2007. A Note on the Flow and Heat Transfer Enhancement in a Channel with Built in Winglet Pair. International Journal of Heat and Fuid Flow, 28(2), 299-305.

[17] Khalled, A. et al.2007. Heat Transfer Enhancement in Hairy Fin System. Applied Thermal Engineer, 27(1):250-257.

[18] Aharwal, K. et al.2008. Experimental Investigation on Heat Transfer Enhancement Due to Gap in an Inclined 
Continuous Rip Arrangement in a Rectangular Duct of Solar Air Heater. Renewable Energy, 33, 585-596.

[19] Şahin, B. et al.2008. Performance Analysis of a Heat Exchanger Having Perforated Square Fins. Applied Thermal Engineer, 28(5-6), 621-632.

[20] Shaeri, M. et al. 2009. Numerical Analysis of Turbulent Convection Heat Transfer From an Array of Perforated Fins. International Journal of Heat and Fuid Flow, 30(2), 218-228.

[21] Güneş, S. 2009. Çeşitli İç Elemanlar Yerleştirilmiş Bir Boruda Isı Geçişinin İncelenmesi. Makina Mühendisliği Anabilimdalı Doktora Tezi , Erciyes Üniversitesi. Kayseri.

[22] Zhang, J., Zhao, Y., Diao, Y., Zhang, Y. 2015. An experimental study on fluid flow and heat transfer in a multiport minichannel flat tube with micro-fin structures. International Journal of Heat and Mass Transfer, 84, 511-520.

[23] Eren, M., Caliskan, S. 2016. Effect of grooved pin-fins in a rectangular channel on heat transfer augmentation and friction factor using Taguchi method. International Journal of Heat and Mass Transfer, 102, 1108-1122.

[24] Yang, A., Chen, L., Xie, Z., Feng, H., Sun, F. 2016. Constructal heat transfer rate maximization for cylindrical pin-fin heat sinks. Applied Thermal Engineering, 108, 427-435.

[25] Badescu, V. 2017. Smooth and non-smooth optimal pin fin profiles beyond the Schmidt optimality assumption and "length-of-arc" approximation, Applied Mathematical Modelling, 47, 358-380.
Acknowledgment

This paper has been presented at the (IATENS'19-The International Aluminium-Themed Engineering and Natural Sciences Conference) held in Konya (TÜRKIYE), October 26-28, 2019. 